\title{
La construcción de la confianza en el trabajo de campo. Los límites de la entrevista dirigida ${ }^{1}$
}

\author{
MARGARITA DEL OLMO \\ Departamento de Antropología. CSIC. Madrid
}

\section{RESUMEN}

El artículo está dedicado a explorar el tema de la entrevista dirigida desde una perspectiva comparativa; ya que contrasta las dificultades y los problemas surgidos en el empleo de esta estrategia metodológica en un trabajo de campo realizado entre los conversos españoles al Islam (1998-2001), con un trabajo de campo anterior (1986 y 1989), con exiliados argentinos a España durante la dictadura militar en su país. El análisis comparativo permite extraer una serie de conclusiones acerca del alcance del empleo de esta metodología antropológica.

Palabras clave: Métodos antropológicos, Entrevista dirigida, Trabajo de campo, Exilio argentino en España, Conversos españoles al Islam.

\section{SUMMARY}

This article deals with the topic of the open interview as a field method in Anthropology. The author explores the advantages and also the limits of the tecnique by comparing two different fieldworks: one caried out among the Spanish people who converts to Islam, between 1998 and 2001, and the other among the Argentinian exiles to Spain during the military rule in Argentina, which was carried out between 1986 and 1999.

Key words: Anthropological Methods, Open Interview, Fieldwork, Argentinian Exile in Spain, Spanish Conversions to Islam.

INTRODUCCIÓN: ¿QUÉ ES UNA ENTREVISTA DIRIGIDA?

Mi contribución en esta monografía, dedicada a presentar y a discutir problemas metodológicos derivados de la práctica de la antropología, va

${ }^{1}$ Este trabajo se inscribe en el proyecto de investigación número BSO2001-2341 del Plan Nacional de Investigación del Ministerio de Ciencia y Tecnología.

RDTP, LVIII, 1 (2003): 191-220 
a estar centrada en el tema concreto de la entrevista dirigida y, especialmente, en las dificultades experimentadas en el transcurso de mi trabajo de campo con los españoles que se han convertido al Islam, realizado entre los años de 1998 y 2001 . Voy a comparar esta experiencia concreta con un trabajo de campo anterior, que tuvo lugar entre 1986 y 1988 con los exiliados argentinos en España durante la dictadura militar en su país (1976 a 1983). El contraste entre los dos casos me va a permitir hacer un análisis comparativo de la misma herramienta de trabajo en dos situaciones muy diferentes, y a través de él ofrecer como conclusión una discusión acerca del alcance de esta metodología.

No creo que una persona que no haya realizado una entrevista dirigida tenga una idea muy clara de a qué nos referimos exactamente los antropólogos cuando hablamos de ella. En disciplinas afines suele citarse como un instrumento de análisis cualitativo, pero se confunde demasiado a menudo con un cuestionario o una entrevista estructurada, quizá porque los propios manuales generales de antropología son poco claros acerca de esta herramienta metodológica. Veamos algunos ejemplos significativos al respecto.

Cultural Antbropology (Ember y Ember 1988) hace una referencia vaga cuando aclara que "el etnógrafo en el campo tiene la oportunidad de conocer el contexto de las costumbres de una sociedad preguntando directamente a la gente sobre ellas y observando los fenómenos que aparecen asociados con esas prácticas". Cultural Antbropology (Kottak 1987), recientemente traducido al español, es un poco más explícito al decir que los etnógrafos, a diferencia de los sociólogos, hablan directamente con los sujetos de su estudio proporcionando a los informantes una estructura que dirija, pero no constriña, la conversación con el interlocutor. Es necesario aclarar, además, que los términos de "entrevista dirigida" han alcanzado en la literatura antropológica española un acuerdo que evita discusiones y ambigüedades, sin embargo, en inglés se emplean para ella distintas expresiones: "open interview", "unstructured interview", "field interview" o simplemente "interview".

Por lo que respecta a la literatura dedicada a cuestiones metodológicas en antropología, se podría citar, por ejemplo la obra de Rusell Bernard, Research Methods in Antbropology (1995). Bernard dedica un capítulo a la "unstructured interview" y la define como una "entrevista basada en un plan claro que el antropólogo tiene constantemente presente en la cabe$\mathrm{za}$, pero que se caracteriza por un mínimo de control sobre las respuestas del informante". Más adelante aclara que "la idea es conseguir que la gente se abra para dejarles expresarse en sus propios términos y a su propio ritmo" (Bernard 1995: 209). En su opinión, una entrevista no estructurada debe incluir las siguientes claves (Bernard 1995: 210-211): 
- asegurar a los informantes su anonimato

- explicar al informante por qué sus opiniones y sus observaciones resultan particularmente relevantes

- aclarar por qué ha sido seleccionada su opinión

- tratar de aprender de la conversación

- pedir permiso para grabar o tomar notas durante la entrevista

Charles Briggs, en un libro titulado How to Ask (Briggs 1986: 6-7) define la entrevista dirigida como "un variado conjunto de actividades de investigación, que incluye desde las entrevistas informales, pasando por las entrevistas abiertas y hasta el uso de instrumentos formales de encuesta en la investigación [...] la recolección de datos debe efectuarse en una situación cara a cara. La interacción debe producirse en un contexto de investigación que implica la formulación de preguntas por parte del investigador".

Personalmente, prefiero explicar cuál es el objetivo de una entrevista dirigida utilizando una metáfora, que es un método explicativo ampliamente reivindicado por la antropología contemporánea. Una entrevista dirigida es una conversación con un interlocutor (la mayoría de los antropólogos actuales se opone al empleo de la palabra informante por las connotaciones de subordinación que implica el concepto) en la que lo que se busca no son respuestas, sino preguntas. Lo que quiero expresar de esta manera es que perseguir preguntas en vez de respuestas permite encontrar significados. Se trata, en definitiva, de un ejercicio de empatía nada fácil de hacer, y para el que tampoco existen recetas que permitan un aprendizaje rápido. Pero mi intención aquí no es subrayar su dificultad sino explicar sus méritos.

Creo que podría resultar ilustrativo contrastar, en este sentido, una entrevista dirigida con un cuestionario. A través de un cuestionario el investigador formula una serie de preguntas, abiertas o cerradas (es decir sobre las que el entrevistado puede o no elaborar), para obtener respuestas más o menos concretas. La información obtenida así es fácil de comparar, e incluso susceptible de ser tratada a través de análisis estadísticos. Una entrevista dirigida, sin embargo, se parece mucho más a una conversación en la vida cotidiana. Los sujetos de la conversación establecen una relación en función de sus intereses y del contexto, y parten de un conocimiento compartido, que el uno supone sobre el otro, a partir del cual se elabora. Surgen malentendidos cuando ese acuerdo sobre el que se parte se supone pero no se comparte.

En una entrevista dirigida se produce el mismo tipo de intercambio, pero es difícil establecer ese acuerdo de partida por varias razones. En 
primer lugar vamos a considerar la posición del etnógrafo. Está buscando aprender acerca de algo que no conoce y, por lo tanto, no puede preguntar directamente sobre ello. Lo que suele hacer es explicar su interés en la conversación, y eso, muchas veces, tampoco resulta fácil. También resulta útil proponer un tema de conversación, o al menos un contexto narrativo que provoque el discurso del entrevistado. Por su parte, éste no sabe qué ofrecer y, a menudo, no entiende las razones del interés por sus opiniones. Si no recibe preguntas, puede resultar para él una situación confusa, puesto que muchos informantes asumen que una entrevista consiste en contestar preguntas ${ }^{2}$.

En mi propio trabajo siempre me ha resultado difícil este punto de partida, y además he comprobado que de él depende muchas veces el transcurso de la conversación. Desafortunadamente, las personas que he entrevistado a lo largo de mi vida prefieren que les explique realmente qué quiero antes de encender el cassette, de manera que este proceso de negociación tan importante y determinante suele producirse "off the record". Hubiera aprendido mucho si hubiera podido hacer un análisis de los discursos en estas situaciones, pero casi siempre la grabación ha comenzado en el momento en que mi informante ha presumido que entendía cuáles eran mis intereses.

La estrategia que suelo emplear es la de provocar una narración sobre una experiencia que presumo en mi interlocutor relacionada con el tema que me interesa, que suele abarcar un periodo largo de su vida, y a través de la cuál es él o ella quien tiene que decidir qué cosas contar y cómo lo debe hacer. Esta forma de preguntar tiene la ventaja de ofrecer una gran libertad a la persona entrevistada. Muchas veces he observado además que construye confianza en la conversación, porque permite, de partida, pensar en eludir lo que considere difícil de explicar, al menos en un principio. También tiene otra doble ventaja: para ellos la de emplazarles en su terreno y para mí la de poder manifestarme ignorante acerca de lo que me hablan y preguntar libremente cuando no entiendo. Es decir que me coloco en un contexto narrativo en el que la persona que me habla es consciente de que desconozco y por ello me tiene que explicar las cosas con mayor detalle del que lo haría en una conversación cotidiana.

De esta forma cada entrevista se convierte en una negociación de un acuerdo que mi interlocutor y yo tenemos que alcanzar antes de dar por

${ }^{2}$ Briggs (1986: 11-20) ofrece un pequeño resumen del uso de la entrevista dirigida en contextos diferentes del trabajo de campo antropológico, tales como las encuestas de los folkloristas, las que emplea la historia oral, la sociolingüística y la sociología. 
terminada la conversación. A lo largo del tiempo en el que transcurre, y éste es muy variable en función de la disponibilidad de la persona entrevistada y de su interés por contar las cosas (mis entrevistas varían entre una hora, las menos, y cinco, muchas más, situándose la media alrededor de las tres). Personalmente cuento con la posibilidad de manifestar acuerdo o desacuerdo, asintiendo, callando, argumentando en contra, intercambiando historias, o simplemente diciendo "ahá". Sobre esta expresión "ahá" y su significado se celebró todo un simposio en la 96. ${ }^{a}$ Reunión Anual de la American Anthropological Association que tuvo lugar en Washington en 1997. Cito este ejemplo para ilustrar la importancia de los distintos métodos que se emplean para que la persona entrevistada continúe produciendo su discurso.

Este tipo de metodología permite a un etnógrafo construir un contexto adecuado para negociar significados, lo que obtiene de este intercambio es un material muy difícil de manejar.

En primer lugar, si se ha tenido la suerte de poder grabar la entrevista, y se ha hecho lo suficientemente bien como para poder escucharla. En este sentido tengo que decir que mi cassette se estropeó, sin que yo lo supiera, en el transcurso de una de las entrevistas más importantes de mi trabajo de campo con los conversos españoles al Islam, la persona con la que hablé murió poco después de la entrevista y el material resultó irrecuperable, pero no he vuelto a grabar sin emplear unos auriculares para escuchar a través del cassette. En primer lugar hay que transcribir la entrevista. Resulta útil hacerlo poco a poco y antes de la siguiente cita con la misma persona, pero no siempre es posible. Algunos investigadores contratan transcriptores. Yo nunca he tenido dinero para hacerlo, pero he aprendido a establecer una relación muy especial con mis largas sesiones de transcripción: la de observar atentamente la relación que estaba entablando con la persona que entrevistaba, prestando atención a los tonos de voz, a los silencios, etc., de manera que al hacer las transcripciones es cuando debo seleccionar distintas posibilidades y tomar las decisiones pertinentes para convertir la palabra en texto. Además, de alguna forma, es cuando disecciono los significados, y selecciono algunos fragmentos para realizar un análisis del discurso.

Existe la posibilidad de pasar los archivos de voz directamente al ordenador si se han grabado digitalmente. Otra alternativa consiste en emplear un programa de reconocimiento de voz en la transcripción, pero no directamente. Como estos programas deben ser entrenados primero, no son capaces de reconocer voces distintas, por lo tanto una persona debe dictar el contenido de la grabación para que sea transcrito por el ordenador. Una vez transcrito el texto, también existe la posibilidad de 
realizar análisis del discurso a través de programas de software diseñados para hacerlo. Ello facilita, si no el análisis en detalle, al menos un tratamiento general. Los que conozco al respecto no se pueden emplear nada más que en inglés NUD*IST ${ }^{3}$, por ejemplo, es uno de los más difundidos, fue creado por una socióloga y un matemático a finales de los años 80; hoy en día está comercializado a través de internet ${ }^{4}$.

Personalmente siempre he encontrado muy útiles las directrices de Teun A. van Dijk (1984, 1985, 1993) pero como he dicho antes, los análisis, hasta el momento, los he realizado yo directamente, lo que no me ha permitido nada más que hacerlos con extractos del texto.

Para ilustrar los argumentos empleados, me gustaría ahora presentar al lector dos ejemplos concretos del empleo de la entrevista dirigida, analizando las ventajas y los inconvenientes de esta herramienta antropológica en el contexto de dos trabajos de campo distintos; el primero de ellos realizado entre los exiliados argentinos en España (1985-1988) y el segundo entre los conversos españoles al Islam (1999-2001). El contraste entre ambos me permitirá, al final, sugerir una discusión sobre los problemas metodológicos derivados de su uso.

\section{EL EMPLEO DE LA ENTREVISTA DIRIGIDA ENTRE LOS EXILIADOS ARGENTINOS EN}

ESPAÑA, UN CASO SIN DIFICULTADES

Cuando realicé mi trabajo de campo entre los exiliados argentinos en España tuve que enfrentarme a una gran cantidad de problemas metodológicos, pero ninguno de ellos estaba relacionado con el empleo de la entrevista dirigida. De hecho, cuando en 1986 inicié el estudio, el exilio había terminado hacía varios años porque la dictadura de la Junta Militar había sido sustituida por la presidencia democrática de Raúl Alfonsín (1983). De manera que a partir de ese año, e incluso antes, cuando a partir de su derrota en la Guerra de las Malvinas la dictadura comenzó a desmoronarse de forma precipitada, los exiliados argentinos en España tuvieron que enfrentarse al dilema de volver a la Argentina (que fue la postura que favoreció el gobierno español financiando, al menos parcialmente, el retorno de algunas personas) o quedarse en España transformándose en inmigrantes. A pesar de que la mayoría se quedó, durante muchos años continuó percibiéndose como exiliada y no como inmigrante. Por este motivo realicé la mayor parte de mi trabajo en España, pero llevé a cabo

\footnotetext{
${ }^{3}$ Richards y Richards (1994) hacen un buen análisis de él.

${ }^{4}$ En Europa lo distribuye Sage Publications.
} 
una pequeña parte en Argentina entre las personas que habían decidido regresar.

Mi interés por el exilio argentino tenía un motivo muy particular, el de emplearlo como caso de estudio en el trabajo sobre la identidad cultural, que fue el tema de mi tesis doctoral. La tesis (del Olmo 1990) proponía, a lo largo de la primera parte, un modelo teórico, y ensayaba sus hipótesis, en la segunda, entre el grupo constituido por los exilados argentinos en España. El motivo de la elección de los exiliados argentinos en particular fue buscar un grupo del que se pudiera presuponer, al menos hipotéticamente, que había tenido que experimentar necesariamente una crisis de identidad. Me pareció que un colectivo desplazado de su lugar de origen para vivir en otro debía haberla sufrido. En un tema tan resbaladizo como el estudio de la identidad cultural, una situación de crisis se presuponía una situación ideal (como en otros tantos casos ilustrados por la literatura antropológica) para trabajar.

En efecto, tal y como descubrí en el transcurso del trabajo, el grupo había sido afectado profundamente por una crisis de identidad, pero ésta no estaba causada, como yo había creído, por su desplazamiento a España, sino por el propio exilio. Ello me condujo entonces a definir el exilio como una situación en la que un individuo, que no contempla como proyecto de vida la posibilidad de emigrar porque sus intereses están puestos exclusivamente en la sociedad en la que vive, es obligado a renunciar a ese proyecto y a abandonar el país. La percepción de esa coerción era muy variable, y tuvo mucha importancia en la forma de vivir el exilio. Algunas personas habían salido directamente de la cárcel, haciendo uso del derecho constitucional de los argentinos de cambiar la prisión por la salida del país cuando éste se encuentra en estado de sitio. Otros huyeron porque sentían que su vida estaba amenazada; la percepción de ese peligro es subjetiva, y de nuevo se vuelve a abrir un elenco de posibilidades variadas: desde huir del asesinato, hasta saber que se formaba parte de determinadas listas que eran el objetivo de la represión militar, o sentirse sofocado por un ambiente que impedía el desarrollo de una vida normal, etc. Esta variedad de posibilidades y sus distintas percepciones, fue precisamente uno de los temas principales en las entrevistas que realicé.

Tal y como he afirmado antes, las entrevistas no me causaron ningún problema, ni en España ni en la Argentina. Conseguí acceder al grupo construyendo una red de relaciones en las que conseguía una cierta confianza con la persona que iba a entrevistar, gracias a la tarjeta de visita que me proporcionaba la identidad de quien me presentaba. De esta manera, el primer proceso de negociación, que consistía precisamente en hacer posible la entrevista, la realizaban por mí mis interlocutores, que me dirigían a 
conocidos y amigos, pero a quienes ellos antes advertían de mi interés. Mi red llegó hasta la Argentina y nunca me faltaron personas para entrevistar.

$\mathrm{Al}$ iniciar las conversaciones, que todos me permitieron grabar con una sola excepción: una persona española que ocupaba un cargo oficial y cuyo trabajo consistía en facilitar la acogida, la integración y eventualmente el retorno de los argentinos expatriados en España, yo pedía a mis interlocutores que me relataran la historia de su exilio, desde el momento que ellos considerasen pertinente, hasta la actualidad. La mayor parte manifestó explícitamente su deseo de celebrar la entrevista y, animados por mi posición externa con respecto a la colonia que habían formado los argentinos en España, abordaron aspectos de su trayectoria de los que antes no habían hablado, o al menos así lo manifestaron. Todos consideraron legítimo mi interés académico por su experiencia y en algunos casos lo valoraron como el único reconocimiento por parte de la sociedad española a su presencia como exiliados en ella.

Tuve la suerte de conversar con verdaderos contadores de historias, personas que articulaban su discurso de una forma magistral. Por ese motivo, la entrevistas fueron experiencias extraordinarias. Tanto fue así que, una vez empleado en la tesis el material pertinente, conservé las grabaciones originales, y viajaron conmigo de un continente a otro, siempre como una presencia significativa en mi cajón de trabajo, y sin atreverme a borrarlas como había prometido, pero elaboré un código de referencia complicado para preservar el anonimato de cada una de las personas. Hasta que un día, empecé a dar vueltas a una idea para trabajar con ellas y, cuando dispuse del tiempo necesario, las convertí en textos y algunos de ellos acabaron convirtiéndose en los capítulos del libro La utopía en el exilio (del Olmo 2002).

Los capítulos integran las dos partes del libro, dedicadas una a los exiliados que se quedaron en España y la otra a los que volvieron a la Argentina, pero cada uno de ellos constituye un texto que trata de reflejar el proceso singular de negociación de significados que tuvo lugar entre mi interlocutor y yo, cuyo objetivo era convencerme de que el proceso de transformación que experimentaron a través del exilio era la única alternativa posible y coherente con el proyecto político que les expulsó del país. Todos consiguieron mi acuerdo sin reservas de que su trayectoria fue, en efecto, la única viable, coherente y honesta. Lo cual resulta muy significativo, teniendo en cuenta que esas alternativas, además de muchas veces contradictorias entre sí, algunas veces resultan totalmente opuestas. Sirva de ejemplo simplemente la propia decisión de volverse a la Argentina o quedarse en España. Desde mi punto de vista en esto es precisamente en lo que consiste una entrevista dirigida. 
En este contexto particular, mis preguntas tuvieron muy poco valor, afortunadamente hice pocas. Voy a poner un ejemplo. Cuestionar a un exilado por qué se ha exiliado, dirige a mi interlocutor a explicarme, no su propia experiencia del exilio, sino las atrocidades políticas y sociales cometidas por la dictadura militar que lo provocó. ¿Cuál fue, entonces la alternativa que sí tenía sentido para que hablara su propia trayectoria?, referirme a una palabra que ni siquiera conocía referida a este contexto: "quiebre", y preguntar: ¿cuándo y cómo te quebraste?, ¿por qué? La palabra "quiebre" la empleaban para hacer referencia al compañero que había "hablado" y delatado a otros durante un proceso de tortura. En mis entrevistas se referían con ella de forma mucho más genérica, pero también más personal; al momento en el que el universo de referencia en el cual se concebía el proyecto político y la propia militancia, y que explicaba la vida en general, dejó de tener sentido, no sirvió más, y se desechó, dolorosamente, por inservible. Inquirir sobre el quiebre personal, significaba preguntar acerca del proceso de transformación que una persona había realizado, cuando el sistema de referencia en el que creía, había hecho crisis y resultaba inadecuado; por lo tanto después de una etapa vivida como una experiencia de confusión y pérdida, el sujeto se embarcaba en la búsqueda de un universo nuevo y capaz de explicar la experiencia vital. Para algunos ello supuso la necesidad de huir de sus propios compañeros que les amenazaban de muerte al querer abandonar la militancia política; para otros, dejar de dividir el mundo en buenos y malos a través de la frontera del compromiso político y encontrar buenos y malos en los dos lados; otros abandonaron para siempre el sentido político de la existencia y se dedicaron única y sencillamente a disfrutar de la vida, comprometerse en luchas políticas distintas, escribir cuentos sobre la experiencia, o simplemente deshacer las maletas siempre dispuestas porque el exilio no podía durar, reconocer la superioridad táctica del enemigo, volver a vivir en el barrio de la infancia.

El relato de esta transformación es precisamente lo que a mí me interesaba, pero tuve que aprender de mis interlocutores a formular las preguntas adecuadas.

\section{PROBLEMAS EN EL EMPLEO DE LA ENTREVISTA DIRIGIDA ENTRE LOS CONVERSOS ESPAÑOLES AL ISLAM}

Sin embargo, esta forma de entender y plantear la entrevista dirigida me causó muchas dificultades en mi trabajo de campo entre los españoles conversos al Islam. En cada conversación se instalaba un desentendi- 
miento mutuo que escalaba progresivamente $y$, a menudo, me obligaba a acabarlas de una forma brusca que me dejaba con una perturbadora sensación de frustración.

Mi interés por los españoles que han decidido adoptar de una forma voluntaria al Islam, como el que tuve por los exiliados argentinos, fue un interés instrumental. De nuevo se trataba de plantear el trabajo como un estudio de caso en el que ensayar mi análisis sobre el racismo, la integración y el multiculturalismo.

Aunque muy pocos lo saben o lo reconocen, España continúa siendo, en términos absolutos, una sociedad de emigración, pero a lo largo de las últimas décadas se ha convertido, alternativamente, en una sociedad receptora de inmigrantes. Y éste sí es un fenómeno conocido y sobreestimado por los medios de comunicación. Los primeros inmigrantes llegaron principalmente de Europa, y hasta fecha muy reciente han constituido la minoría más grande en términos relativos, y de Latinoamérica.

Dado, por un lado, mi interés en los temas relacionados con la integración y la actitud de la comunidad receptora hacia los inmigrantes, y, por otro, la construcción de la memoria colectiva sobre el proceso de formación y desarrollo histórico de España (véase al respecto Manzano 2000), es lógico que dedicara mi atención al tema del Islam y a su capacidad de integración en la sociedad española, así como a la posibilidad de ésta para integrarlo. Las polémicas recientes en la prensa han venido a confirmar este interés.

Para hacer un análisis significativo de la capacidad de la sociedad española para integrar o no la religión musulmana, se me ocurrió elegir como caso de estudio a los españoles conversos al Islam. Presentaba varias ventajas y algunos inconvenientes. Entre las ventajas debo señalar el hecho de que los conversos, como españoles, conocen perfectamente la imagen que la sociedad tiene del Islam, como musulmanes están poniendo a prueba constantemente, a través de su vida diaria, los límites de los procesos de cambio y adaptación. Entre los inconvenientes: la sobredimensionada atención que los conversos prestan a su nueva experiencia religiosa, que dirige cada uno de los aspectos de su vida, mucho más que en el caso de los musulmanes que lo han sido siempre.

Es muy difícil estimar la cifra total de españoles que se han convertido al Islam, por dos motivos, fundamentalmente. Los censos españoles no preguntan acerca de la afiliación religiosa y, además, según el derecho islámico, la conversión es un acto privado para el que el converso no necesita más testigos que Dios. La ONU estimaba recientemente el número de conversos españoles al Islam en unos 5000 (Fernández 2001: 25 ), otras fuentes ascienden el total a $30.000^{5}$. La disparidad entre estas 
cifras ya está indicando que son muy aproximativas y que deben manejarse con cautela. De todas maneras, las conversiones se producen casi a diario, y también el abandono de la nueva religión, de manera que es muy difícil citar cantidades aproximativas.

Una persona se convierte a Islam recitando una fórmula que se conoce como la sahada, y que, traducida al español dice: "No hay más Dios que Dios y Muhamad es su profeta". Una vez formalizada, el neófito tiene dos alternativas de vida en España: puede residir en una comunidad pequeña formada exclusivamente por musulmanes, como las que existen en el sur de España, principalmente en Granada, entre las que Pedro Antonio Sánchez (1995) ha realizado un trabajo de campo, o puede continuar viviendo como musulmán en una sociedad mayoritaria que no lo es.

Algunas personas que se han convertido al Islam en pueblos pequeños, sin muchas posibilidades para atender las exigencias de su nueva religión por falta de lugares de culto y de comunidades musulmanas en las que aprender a vivir de una forma distinta, han emigrado a grandes ciudades, especialmente a Madrid que cuenta con un número importante procedente, sobre todo, de la inmigración. En Madrid existen dos mezquitas oficiales, una cantidad de oratorios improvisados, carnicerías islámicas donde comprar la carne sacrificada según las normas de su religión, etc. Entre este grupo es en el que yo he realizado mi trabajo (1999-2001) y, aunque no exclusivamente, la mayor parte de mis interlocutores han sido mujeres.

La Mezquita de la M-30 o Centro Cultural Islámico, que es su nombre oficial, me ha proporcionado un lugar de encuentro, y la mayoría de mis contactos los he hecho en las clases para conversos españoles que imparte el imán de la mezquita los sábados por la mañana, con traducción simultánea al español. Sin embargo, debido a los intereses de mi trabajo, he realizado entrevistas no sólo entre ellos, sino (en aquellas ocasiones en las que he tenido la oportunidad) entre sus familiares y amigos. Desgraciadamente estas oportunidades no han sido frecuentes, ya que la mayoría, o bien guarda en secreto su conversión, o mantienen unas relaciones tensas y difíciles con sus familias.

Al igual que entre los exiliados argentinos, lo que me interesaba aquí era el proceso de transformación de sus vidas a partir de la conversión,

\footnotetext{
${ }^{5}$ La cifra de 30.000 conversos al Islam en España la ofrece el artículo, "La colonia islámica en España reivindica su ideario frente a la barbarie". El Correo, que se puede consultar en internet (http://servicios.elcorreodigital.com/pag230901/mundo/ mundo015.htm), firmado por C. Calvar. Madrid.
} 


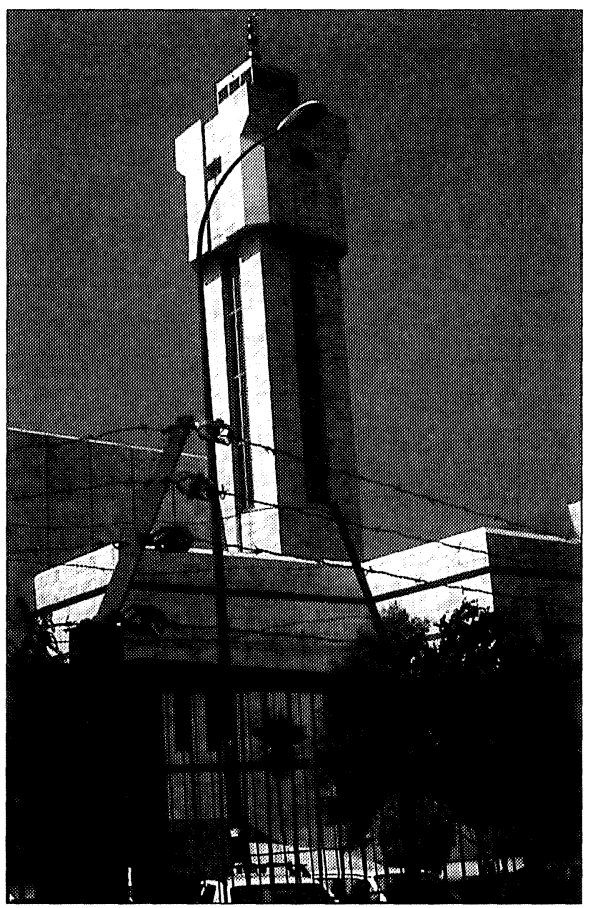

FIGURA 1.-Centro Cultural Islámico de Madrid. Vista general.

y las dificultades que habían experimentado (o no) para integrar en sus vidas cotidianas y en sus entornos sociales los nuevos hábitos y costumbres derivados de sus nuevas creencias y prácticas religiosas. De manera que, de la misma forma que entre los argentinos, trataba de plantear mis entrevistas pidiendo un relato amplio acerca de su conversión, desde sus primeros contactos con el Islam, hasta el momento presente. Todo ello para tratar de conseguir una narración articulada de las circunstancias que mis interlocutores considerasen significativas en el proceso de adopción de la nueva religión. Sin embargo, a diferencia de mis entrevistas con el grupo de exiliados argentinos, los conversos planteaban la conversación como un ejercicio dialéctico en relación con mi propio papel de no musulmana. En este esquema sólo me permitían dos posturas, excluyentes una de la otra: en contra de sus argumentos o a favor de ellos.

Los conversos trataban de demostrarme, como en su día lo hicieron los argentinos, que su recorrido vital era el único posible, y que su proceso de transformación era una consecuencia de él. Pero a diferencia de lo que ocurrió entre los exiliados, para los conversos, la única forma legítima de demostrar mi acuerdo era a través de mi propia conversión. Algunas excepciones notables han confirmado esta expectativa general.

Uno de los problemas, que tuvo una influencia determinante en el desarrollo de mis relaciones posteriores con ellos, era que tanto mi presencia como mi comportamiento inducía a malentendidos en los primeros contactos. Voy a poner un ejemplo. La primera vez que asistí a las charlas para conversos españoles tenía una cita previa con uno de ellos, pero esta persona no se presentó. A pesar de todo, decidí ir a la clase. Cuando entré en la sala encontré una mesa larga, dispuesta a modo de estrado, y colocada paralelamente a la pared del fondo, en la que supu- 
se se sentaría la persona o personas que se iban a dirigir al público. Y ésta fue la única suposición correcta que hice. El resto de la sala estaba repleta de sillas de plástico dispuestas en filas de cara a la mesa. Elegí una de ellas hacia el medio de la habitación que pensé que me iba a ofrecer un lugar discreto pero con plena visibilidad de la mayor parte de la sala y de la mesa. Cuando fue llegando el público me encontré curiosamente rodeada de hombres, excepto a mi espalda, donde se sentaron mujeres. Enseguida se acercó una mujer a hablar conmigo y a sugerirme con mucha amabilidad y delicadeza que me trasladara algunas filas hacia atrás para sentarme con ella y su grupo. Me pareció un golpe de suerte y un

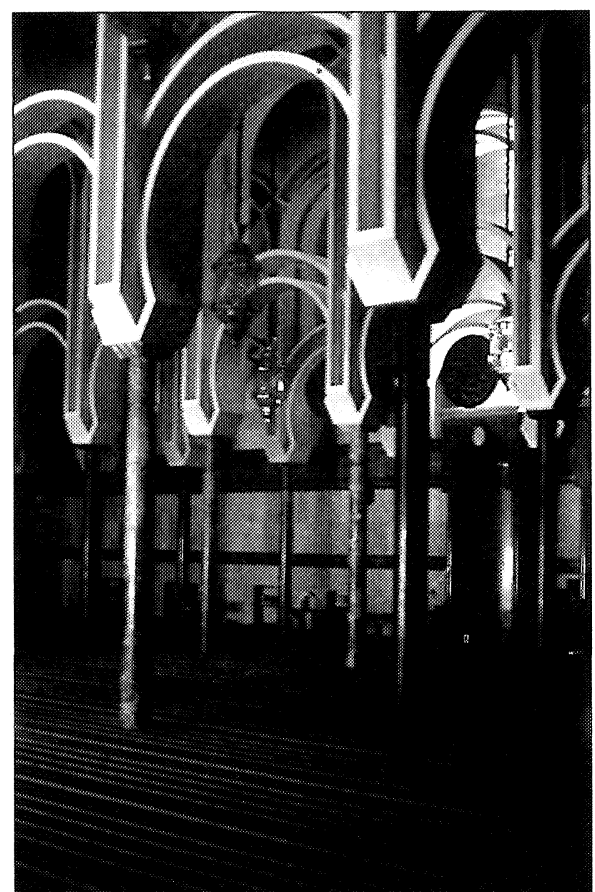

Figura 2.-Centro Cultural Islámico de Madrid. Sala de oración de los hombres. amable gesto hospitalario, pero fue mucho más complicado que eso. Al salir de la clase, el grupo de mujeres con el que me había sentado me rodeó interesado por mi presencia y pronto descubrí que me habían identificado, erróneamente, con una conversa.

Lo que había ocurrido sin que yo me hubiera dado cuenta era que las sillas de la sala no estaban directamente apoyadas en el suelo, sino que descansaban sobre una alfombra, en realidad sobre dos enormes alfombras dispuestas una detrás de la otra. Cada alfombra estaba delimitando un espacio simbólico: la primera y más cerca de la mesa, destinada a los hombres, la segunda a las mujeres. Al elegir mi sitio me había colocado en la última fila de sillas de la alfombra de los hombres, transgrediendo así la separación espacial en función del sexo. Esta señal alertó a un grupo de mujeres que supuso que mi mala colocación era atribuible a mi ignorancia de las reglas de distribución del espacio; por otra parte, el interés que demostraba tomando notas en mi cuaderno, fue malentendido como derivado de mi voluntad de convertirme al Islam. Su gesto de invitación tuvo la intención, no hecha explícita, de 
impedirme cometer un error y de guiarme a través del complicado conjunto de diferencias que distinguen el comportamiento de un musulmán del que no lo es, en el interior de un recinto religioso. Era una forma amable de informarme y una estrategia sutil para enseñarme las normas.

Traté de deshacer el malentendido que provoqué en el momento en el que fui consciente de él, pero no fue nada fácil, y en algunos momentos llegó a parecerme imposible. Les expliqué que mi interés por la conversión al Islam era un interés profesional y me vi obligada a hacer explícita incluso mi postura personal con respecto a la religión en general. Sin embargo, ellas se empeñaron en interpretar que mi acercamiento al Islam, independientemente de la etiqueta que yo le quisiera poner, como señal de que, de alguna forma, Dios me había llamado y era Él quien había inculcado en mí esa curiosidad, por extrañamente que pudiera manifestarse. Y que aunque yo misma no me considerase una conversa, algún día podía llegar a serlo, porque ninguna persona puede predecir su propio futuro. Les dije, honestamente, que lo dudaba mucho, aunque admití mi imposibilidad de saber qué iba a pasar con mi vida en términos absolutos. Este mínimo acuerdo fue suficiente para ellas, y desde ese momento empezaron conmigo un proceso de adoctrinamiento en el que me sentí francamente incómoda.

Esperaban de mí que leyera los folletos que me prestaban con sumo interés, y yo lo hacía, pero sin poder responder exactamente a sus expectativas. Esperaban, además, que debatiera cualquier punto de doctrina con el que no estuviera de acuerdo. Pero nada más lejos de mi intención. Con el tiempo conseguí convencerlas de que, en efecto, mis posibilidades de convertirme al Islam eran bastante remotas y que mi curiosidad no iba dirigida a su religión sino que tenía un motivo profesional. En ese momento fue precisamente cuando ellas perdieron su interés por mí. Me sentí entonces siguiendo un camino imposible y llegué, de hecho, a plantearme la posibilidad de abandonar el trabajo.

Pero entonces sí tuve un golpe de suerte. Una de las personas del grupo estaba haciendo una tesis doctoral en la misma institución para la que yo trabajaba. Con ella construí una relación diferente. Teníamos metas comunes y fue capaz de entender mis motivos profesionales. Nos intercambiamos favores y en ese intercambio, en algún momento, llegó a quedar incluido mi trabajo. Ella fue el único miembro de aquel grupo que aceptó mi papel con respeto, y a partir de ese respeto empezó a acompañarme a los sitios, a contestar mis preguntas, y a facilitarme encuentros, conversaciones y discusiones con personas que ella conocía y que creía conveniente que conociera yo. 


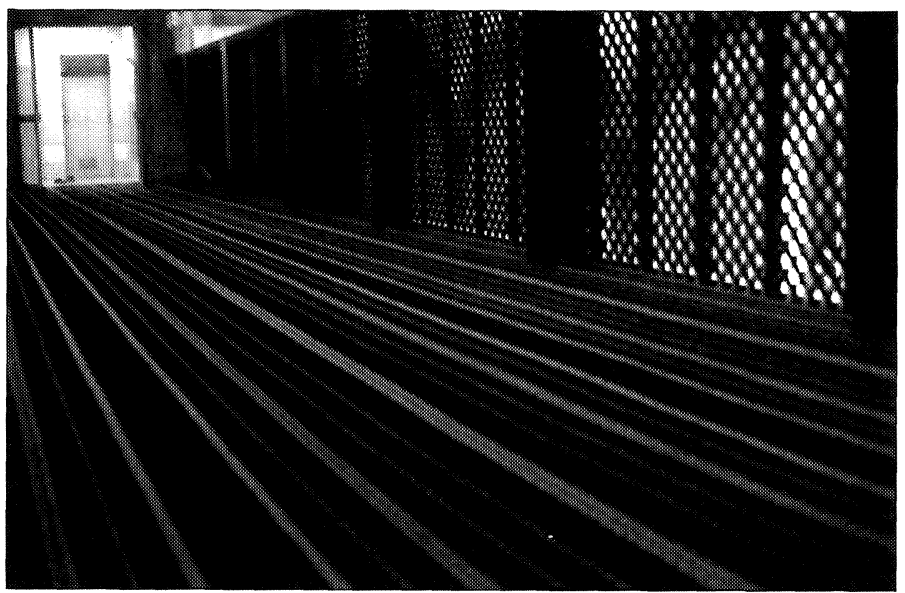

Figura 3.-Centro Cultural Islámico de Madrid. Sala de oración de las mujeres.

Se convirtió en una estupenda tarjeta de visita que hizo posible que, al igual que con los argentinos, yo construyera una red de relaciones personales entre el grupo de conversos. A pesar de ello, la mayor parte de mis problemas quedaron sin resolver, lo que, desde luego, ha tenido una influencia importante sobre el alcance de la investigación que he realizado (del Olmo 2000, 2001a, 2001b y en prensa.). Me gustaría discutir aquí algunos de ellos, directamente relacionados con el objetivo de esta monografía.

La problemática derivada del transcurso del trabajo de campo tiene que ver con la dificultad de negociar significados a través de una frontera religiosa. Estoy empleando la palabra frontera en un sentido metafórico, puesto que las vidas de los conversos al Islam en Madrid se encuentran profundamente interpenetradas por el mundo no musulmán; sin embargo, la he utilizado porque me permite reflejar, en parte, mi experiencia a lo largo del trabajo, cuando cada elemento de la vida cotidiana es explicado por ellos exclusivamente en términos de su experiencia religiosa, incluso su vida anterior a la conversión. Las entrevistas dirigidas que he realizado entre ellos lo reflejan muy bien.

Salvo contadas excepciones, la mayoría de los informantes no me ha permitido grabar la entrevistas. La explicación que me han ofrecido era la de que se encontraban incómodos hablando delante de un cassette. Sospecho, sin embargo, que la falta de interés por un trabajo que no tenía sentido en el interior de su mundo religioso, una vez despejadas la expectativas sobre mi propia conversión, ha influido de forma determinante también en esta negativa. Creo que además puede reflejar una 
cierta desconfianza, lógica de acuerdo a unos parámetros que me desproveían de sentido.

Todas la entrevistas han comenzado con una larga explicación, por mi parte, acerca de los motivos de mi trabajo, de mi interés por analizar las posibilidades de la sociedad española para integrar las diferencias de comportamiento relacionadas con la religión musulmana. El único valor positivo que le han atribuido, y en algunos casos ha sido un valor genuino y hasta profundo, ha sido el de dar a conocer al resto de la sociedad española el fenómeno de la conversión al Islam que está teniendo lugar en su seno, un fenómeno, en su opinión, cada vez más generalizado. Éste es un factor muy importante, puesto que la mayoría de los conversos encuentra progresivamente legitimado y afirmado su propio recorrido vital cada vez que se produce una nueva conversión.

Como en el resto de las entrevistas dirigidas que he realizado a lo largo de otros trabajos, yo era consciente de que no conocía las preguntas apropiadas para obtener las narraciones de sus experiencias vitales. En este caso, por ejemplo, la cuestión ¿por qué te has convertido al Islam?, pregunta que afortunadamente nunca hice, no sólo era poco adecuada para conseguir mis propósitos, sino además, discriminatoria. Curiosamente es la que más me ha repetido el público, evidentemente no musulmán, cada vez que he impartido una charla sobre este trabajo. Ahora bien, ¿por qué la consideran negativa? Simplemente porque implica una sorpresa y porque, así formulada, se interpreta como la petición de una justificación: como si la conversión fuera, en sí misma, un comportamiento desviado de la norma, y que por lo tanto requiriera una explicación. Por este motivo es por el que los no musulmanes la repiten con una cierta asiduidad, ya que, con la misma frecuencia, consideran que la conversión al Islam en la España contemporánea supone una desviación del comportamiento razonable, y no sólo eso, sino un paso atrás en el proceso de modernización de las estructuras sociales del país. Los conversos conocen esta suposición, porque también la han compartido ellos mismos, por ese mismo motivo la rechazan y piensan que está relacionada con la imagen negativa del Islam, generalizada en las sociedades occidentales.

El trabajo que he realizado me permite afirmar que las posturas más enfrentadas con la aceptación del Islam en el seno de la sociedad española identifican las relaciones entre los sexos en esa religión con un pasado reciente de dominación masculina que sólo a lo largo de los últimos años ha empezado a confrontarse y a transformarse. Se trata, en definitiva, de un replanteamiento del acceso al poder por parte de ambos sexos, que se considera, hoy en día en la sociedad española, como más igualita- 
rio de lo que era sólo hace algunos años. Esta perspectiva, unida al escaso conocimiento de la religión musulmana, que parte muy pocas veces de una experiencia personal y que en la mayoría de los casos se encuentra mediatizada por los medios de comunicación y por la construcción de la historia española, en particular, en relación a los musulmanes, así como por una generalizada percepción negativa de esta religión en las sociedades occidentales, entiende mucho mejor la conversión al Islam de un hombre que la de una mujer, a quien se considera víctima de un reparto de poder desequilibrado y desventajoso. De manera que la conversión religiosa de una mujer sólo se justifica por motivos de matrimonio, y no se entiende como una

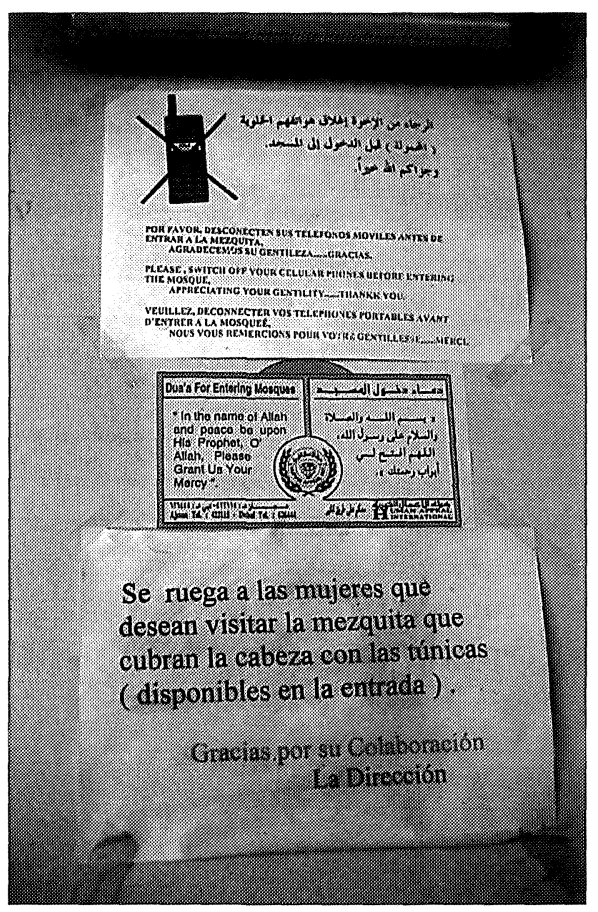

FIGURA 4.-Centro Cultural Islámico de Madrid. Aviso sobre la indumentaria de las mujeres. de un poder que se le presupone en la sociedad española, ya que se cree no sólo que ella lo va a perder a raíz de su conversión al Islam, sino que además su actitud implica un desafío a una posición penosamente conseguida.

Por supuesto las mujeres conversas desafían estas percepciones, aduciendo que se sienten mucho más respetadas como mujeres siendo musulmanas que no siéndolo.

La justificación por matrimonio es, además, una idea errónea. Ya que, según el derecho islámico un hombre musulmán puede casarse sin problemas con una mujer judía o cristiana, pero, sin embargo, una mujer musulmana sólo puede hacerlo con un hombre musulmán. De manera que es al contrario, ya que, como a las españolas se las considera católicas, no deben cambiar de religión para contraer matrimonio con un musulmán, independientemente de cuál sea el compromiso personal que mantengan con la misma. Conozco casos de conversos hombres que han adoptado el Islam para casarse con una musulmana. Los casos de mujeres convertidas a raíz del matrimonio son mucho más esporádicos y, los que en concreto he registrado, se han producido, después de una deci- 
sión voluntaria de la mujer. Las conversiones de las mujeres que me han sido referidas se han producido de forma individual y voluntaria, por motivos personales, y sólo después de una práctica religiosa han buscado una pareja musulmana. Estas mujeres siempre me han relatado sus conversiones en relación con su experiencia vital.

La Asociación de Mujeres Musulmanas de Barcelona ha realizado un estudio sobre las conversiones al Islam en España, y de una muestra de 70 personas ha elaborado una clasificación con las variantes de la conversión. Identifican seis tipos de conversiones: intelectual, mística, afectuosa, experimental, revivalística y obligatoria. Según su análisis, la mayoría de los casos responden al tipo intelectual, es decir, han sido la consistencia lógica y la coherencia del Islam como camino de vida los motivos principales que las decidieron a convertirse. El segundo grupo más numeroso es el que denominan afectuoso y en él incluyen las que se han producido como consecuencia del contacto amistoso con musulmanes $^{6}$. Este análisis concuerda con mis propias percepciones.

A través de mi trabajo, he identificado tres etapas en el proceso de conversión, y las he denominado: Las señales de la llamada, en la que mis interlocutores me relatan sus experiencias significativas anteriores a la conversión pero explicadas a la luz de ella; El proceso de aprendizaje para la conversión, que comienza cuando el converso decide adoptar el Islam como religión (independientemente del momento preciso en el que formalice la conversión) y cuando decide comenzar un proceso de aprendizaje que, teóricamente, deberá durar el resto de su vida; por último $L a$ entrada en la comunidad musulmana, en la que el converso es recibido por los miembros de la misma.

Mi principal interés en estos relatos estaba relacionado con las dificultades de ajuste, a partir de la conversión, en relación con sus entornos sociales. Este interés resultaba poco significativo para mis interlocutores, puesto que explicaban, por ejemplo, los problemas surgidos en la relación con sus familias, como pruebas de Alá para verificar la sinceridad y la profundidad de su conversión. Por este motivo, mi interés por sus dificultades carecía de sentido, y mis explicaciones también. Por su parte, mi escasa atención a los temas de doctrina y mi negativa a discutirlos, les producía una sensación de exasperación y les inducía a considerarme una persona poco curiosa, a la que las preguntas trascendentales sobre el sentido de la vida no le creaban dificultades porque debía ser una persona poco cultivada intelectualmente. Esa percepción suya de mí

${ }^{6}$ Los resultados de este estudio se encuentran resumidos en internet: http:// www.webislam.com/98/30_06_05HTM 
me irritaba profundamente y la frustración que me producía el hecho de argumentar en contra me obligaba a perder las riendas de la entrevista dirigida. Mis entrevistas solían acabar siendo sus entrevistas, y era yo quien, a menudo, se transformaba en entrevistada. Sin embargo, el traslado de poder que ello entrañaba me ha resultado, a largo plazo, muy educativo. Como antropóloga me ha proporcionado una experiencia significativa para contribuir, desde el análisis de mi papel, a algunos de los debates contemporáneos en la disciplina que han puesto en tela de juicio certezas aceptadas tradicionalmente, tales como el concepto de cultura, el enfoque holista, el papel del antropólogo, la construcción de la totalidad en el trabajo de campo, los límites de la traducción y de la interpretación, el sentido de la escritura etnográfica o el objetivo del trabajo de campo. Algunas de estas cuestiones son abordadas por los autores de esta obra colectiva. Yo voy a detenerme en aquellas directamente relacionadas con los problemas surgidos a lo largo del trabajo de campo descrito, para contribuir a la discusión metodológica que esta obra propone.

\section{CONCLUSIONES: ACERCA DEL ALCANCE DE LA ENTREVISTA DIRIGIDA}

En líneas generales, mi trabajo entre los conversos ha supuesto una exploración de los límites del empleo de la entrevista dirigida cuya trascendencia creo que plantea problemas relevantes a la disciplina en general y a mi papel como investigadora, en particular.

Veamos en primer lugar las consecuencias relacionadas con mi propio papel. En este punto creo que ha quedado suficientemente claro que yo no soy una conversa, ni a ésta ni a ninguna otra religión, y que el hecho de defender esta afirmación me coloca irremediablemente y sin ninguna duda, fuera del grupo, de la misma forma que el hecho de no ser una argentina exiliada me hacía ser una persona ajena al grupo de los exiliados. Esta posición externa con respecto al sujeto de estudio ha sido alentada por la antropología clásica asumiendo que presuponía un distanciamiento a cambio del cual se obtenía una perspectiva neutral de la que se derivaba una cierta objetividad. La mayor parte de los antropólogos actuales ha renunciado explícitamente a este intento de objetividad de la disciplina, reclamando la etiqueta de oficio humanista para la etnografía, con la que se encuentran más cómodos que con la de ciencia social.

Mi postura de no conversa no ha sido, desde luego, una posición neutra para los conversos, sino todo lo contrario, ya que ha reclutado los mayores esfuerzos de mis interlocutores para atraerme al seno de su 


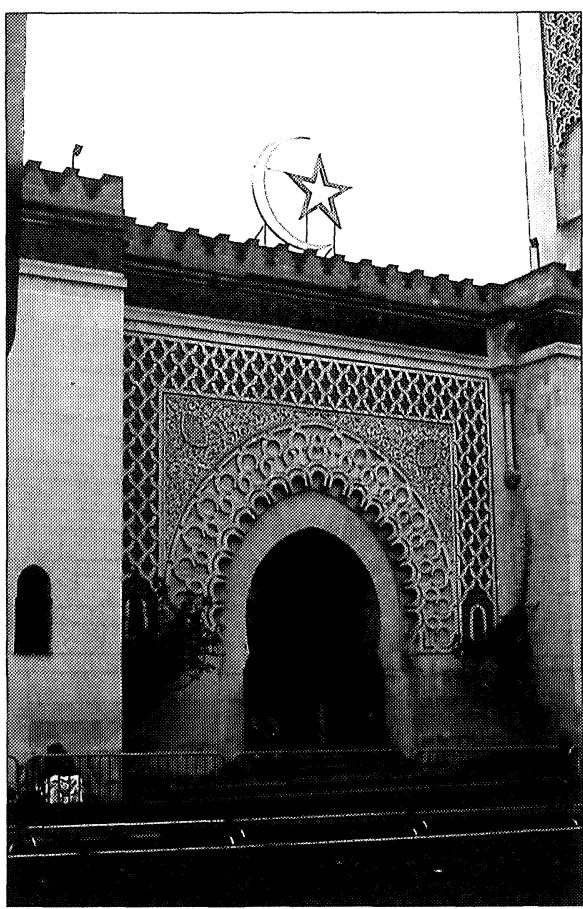

FIGURA 5.-Mezquita de París. Entrada. grupo. Ello ha determinado, profundamente, la naturaleza de las entrevistas dirigidas que he realizado, tanto en su formato como en su contenido, siendo éstos dos elementos relacionados. De manera que sus resultados no pueden ser entendidos sin tener en cuenta el papel que he jugado con respecto al grupo. Esta declaración supone una renuncia absoluta al concepto de "validación" que muchos autores reclaman (Bernard 1995 es un ejemplo reciente de esta tendencia), es decir, a la idea de que las respuestas que se obtienen a través de una entrevista dirigida deberían ser las mismas independientemente de quién fuera el investigador que las haya provocado.

Los límites del grupo analizado, por otra parte, resultan muy resbaladizos ya que no coinciden desde una perspectiva interna con los de una percepción desde el exterior. El grupo de conversos entrevistado se considera perteneciente a una comunidad simbólica transnacional que comparte el Islam como religión (del Olmo en prensa) y que le proporciona un identidad concreta transgrediendo todo tipo de fronteras nacionales y sociales. Pero no se considera ajeno al resto de los no musulmanes, puesto que les ven como miembros en potencia, es decir, como miembros que podrían llegar a serlo. Las conversiones que continúan observando refuerzan esta postura.

Desde fuera del grupo, la sociedad considera a los conversos una anomalía, una excepción con respecto a la norma (lo que, por lo tanto, confirma la norma), se les extranjeriza identificándoles con la comunidad musulmana que procede de la inmigración y de la que se espera, en términos generales, que vaya abandonando sus prácticas religiosas, aunque sea de forma paulatina, se adapten a las costumbres de la sociedad mayoritaria y se beneficien con ello de este proceso de modernización de las estructuras sociales españolas que son, no sólo una esperanza de futuro, sino un ingrediente importante de nuestra imagen presente. 
Por otra parte, el proceso de traducción, considerado por la perspectiva clásica como el objetivo último del trabajo de campo, ya que se trata de explicar y dar sentido para el "nosotros" a las diferencias observadas en esa categoría etiquetada con el término "otros", ha resultado, en el caso concreto que me ocupa, una empresa prácticamente imposible; la frontera religiosa, pues hemos visto que no funciona como frontera de grupo vista desde su interior, pone un límite al proceso de negociación de significados y los distorsiona, de manera que una explicación a un lado de ese límite carece totalmente de sentido en el otro, y viceversa.

Espero que estos tres aspectos sobre las consecuencias de los

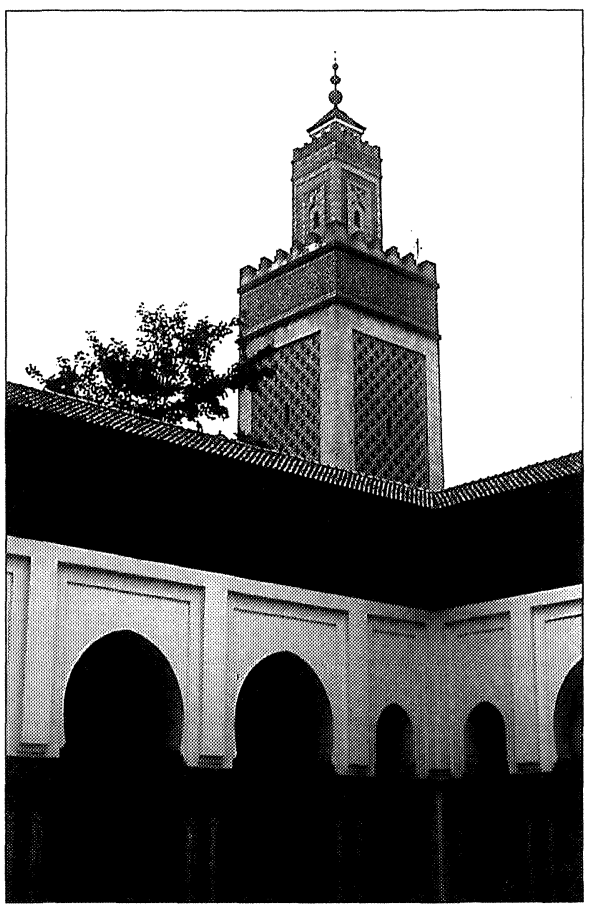

Figura 6.-Mezquita de París. Detalle del patio. límites de trabajo, resulten suficientemente significativos como para argumentar que los problemas metodológicos experimentados a lo largo del trabajo de campo entre los conversos, resultan trascendentes para plantear algunas cuestiones de fondo en la disciplina antropológica.

El trabajo de campo no permite siempre, como no lo ha hecho en este caso, identificar un grupo ni considerarlo un universo en sí mismo, porque las relaciones que establecen las personas no están delimitadas por las fronteras. De manera que no es posible ni teórica ni metodológicamente aislar siempre un caso de estudio, sino que resulta más interesante y revelador entenderlo en un continuo social.

La posición del investigador no es nunca una posición de observador, ya que, al menos en este caso, ha determinado profundamente la producción etnográfica, porque ésta es, nada más y nada menos, el resultado de un proceso de interacción que consiste en negociar continuamente las posiciones y las expectativas mutuas entre el entrevistador y los entrevistados.

Algunas veces la traducción se convierte en una empresa imposible porque, si se me permite emplear una comparación, algunas lenguas tie- 
nen palabras asociadas a conceptos y a experiencias que no existen en otras y viceversa. En determinados casos parafrasear no sirve de nada, simplemente ciertos significados sólo tienen sentido en su propio contexto. A pesar de la dificultad que entraña asumir esta evidencia insoslayable, creo que es necesario reivindicar para ellos un respeto y no tratar de trasladarlos de una manera distorsionada.

Ninguna de estas limitaciones, por molestas que puedan llegar a ser cuando se experimentan, invalidan, en mi opinión, el trabajo de campo, si se concibe la antropología como una disciplina dedicada a plantear preguntas sobre las relaciones que establecen los seres humanos, por efímeras, difíciles e incompletas que éstas puedan llegar a resultar y a percibirse. Quizá los fragmentos nunca sean suficientes para construir un todo, pero resultan interesantes en sí mismos como tales si se les presta la atención suficiente.

\section{DEBATE DE ALGUNAS IDEAS}

Paz Gómez: A mí la entrevista dirigida me da la sensación de ser una escena en la que hay actores o actantes y pueden existir oponentes, facilitadores, donantes, ayudantes y fases hasta llegar al resultado final que es que nos digan lo que nosotros queremos saber, porque queremos saber algo. Eso quiere decir que, por un lado, hay que intentar que el otro participe en nuestro interés, y si no le interesamos no nos va a contar nada. Yo te quería preguntar: en esa escena que describimos en la que hay actores, sonidos, vestuario, ¿qué hacemos con todo el lenguaje gestual? Porque desde la ropa, nuestra sonrisa, nuestra cara... Es decir, estamos todo el rato hablando de un papel de reflexión, pero de reflexión de la palabra, en la que seguimos poniendo lo primero de todo, y si es en un texto, itodavía vale más! Pero a mí me parece que en el oficio nos deberían incluir algún tipo de recursos sobre cómo provocar la empatía.

Margarita: Yo estoy de acuerdo contigo en que no todo el mundo tiene por qué participar de nuestro interés, por qué no, pero cuando ese interés significa hablar o no hablar con ellos: jo les consigues interesar de alguna manera o se acabó la entrevista! No hay entrevista y no hay trabajo posible. Evidentemente que el lenguaje gestual y toda la escena tiene muchísimo que ver. ¡Yo ya tengo bastante con lo que escucho! Me encantaría que pudiera venir alguien conmigo y se dedicara a ello, pero yo ya no puedo más.

Paz Gómez: No, lo que estoy diciendo es plantearse uno mínimamente antes de entrar cómo se presenta porque, aunque sea de manera no di- 
recta, va a influir en su percepción de mí. A eso me estoy refiriendo, no a que vayas a hacer un análisis gestual.

Margarita: Lo que pasa es que es bastante incontrolable porque se puede predecir algún tipo de regularidades en la escena, pero hay montones de cosas que se escapan: recuerdos, transferencias, etc., que no se pueden prever. El azar y la suerte tienen mucho que ver.

Paz Gómez: Pero yo no digo que estés todo tiempo pendiente pero sí que lo incluyas como un elemento de pensamiento.

Margarita: Yo creo que uno se prepara para una entrevista conscientemente, como para cualquier relación social que te importe.

Paz Gómez: Pero lo que digo

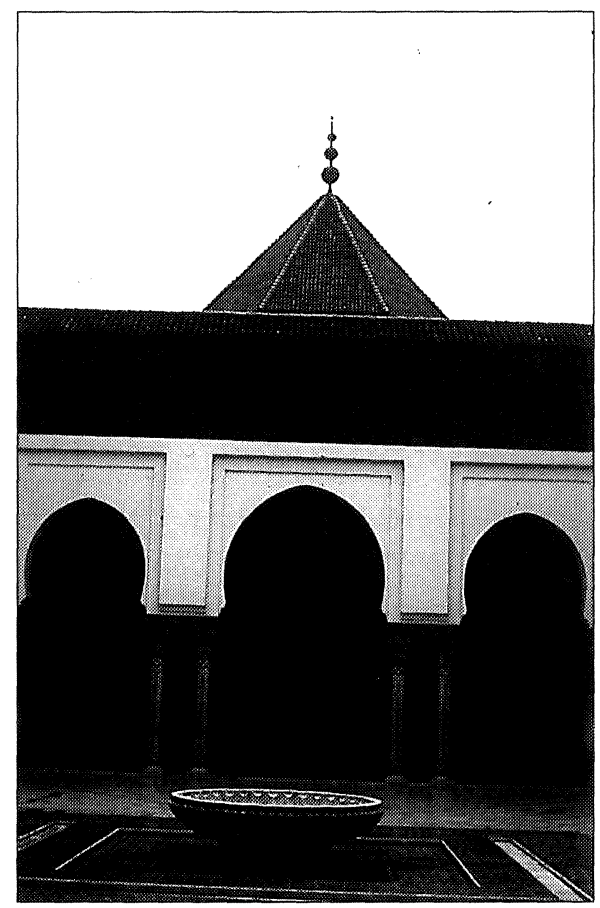

FIgURA 7.-Mezquita de París. Detalle del patio. es que hay un margen muy, muy, muy amplio que es imprevisible en todo este trabajo.

Margarita: ¡Por supuesto! Yo creo que eś algo que se ensaya continuamente y si hay algo que hacemos las personas es establecer relaciones.

Marisa González: Me da la impresión de que tenemos cierta tendencia a estar muy obsesionados con la idea del control. Tal y como Paz plantea es una puesta en escena y como tal es irrepetible y hay cosas que se te van a escapar necesariamente. A mí me parece también interesante el tema de formas de preguntar: cada comunidad y cada estructura lingüística tiene su propia lógica, pues ese tipo de cosas tienen una influencia determinante si uno no las maneja. Hay grupos humanos en los que la pregunta directa no cabe y hay que armar toda una especie de circunloquio y entrar por otro lado.

Margarita: Por eso yo creo que la entrevista dirigida es un instrumento particularmente valioso. Yo creo que una entrevista dirigida no debe hacer preguntas, porque pregunta que hagas, error que cometes. El problema es cómo sortearlas, sobre todo cuando las personas que se entrevistan están esperando preguntas. Pedir relatos, que no es lo mismo que hacer preguntas, y hacer que la gente articule, desde mi punto de vista 
es una estrategia excelente en una entrevista dirigida. Lo que se obtiene es un tipo de información muy difícil de tratar, pero por otro lado tiene una gran profundidad y una gran riqueza.

Marisa González: ¿Qué pasa con los silencios, cuando la conversación se interrumpe?

Margarita: Hay muchos silencios en las conversaciones y son incómodos, pero también hay que aprender a no incomodarse con los silencios. Porque ¿qué significa un silencio?, puede ser un indicio de que la conversación se va a acabar, y entonces uno piensa, ¡caramba! este señor me ha contado aún muy pocas cosas, ¿cómo puedo yo provocar esto? Pero a lo mejor si respetas el silencio estás construyendo otro tipo de confianza con la persona. Tampoco se trataba, por ejemplo en el caso de mi trabajo con los argentinos, de que me contaran detalles escabrosos, que es lo que esperaban que yo hiciera: por experiencias en la cárcel, tortura, etc. jJamás lo hice! Y sí perdía algo importante pues... Creo que esos límites son más importantes que lo que pueda obtener a cambio.

María José Rubio: A mí lo que me parece muy difícil es que cuando uno aborda este tipo de trabajos se tiene que desprender de cualquier tipo de ideología, de nuestra maleta vital que contiene determinadas formas de pensar.

Margarita: Yo pienso que no hay que dejar la maleta en casa, hay que llevarla a la entrevista, de una manera respetuosa, pero uno no puede mentir. Muchas veces lo que la persona entrevistada espera es un intercambio de historias, intercambio de opiniones y un cierto acuerdo. Una entrevista consiste en establecer una relación, provocada por la persona que tiene el interés, y uno no tiene otra manera de establecer una relación más que con lo que tiene dentro de la maleta.

Matilde Fernández: Yo creo que un antropólogo no puede hacer un trabajo sobre algo que le horrorice, es imposible.

Margarita: Yo personalmente nunca creí que llegara a trabajar sobre el Islam, no porque no me gustase, sino porque tenía una serie de ideas sobre el Islam que no me gustaban. Sin embargo sí me interesaba. Yo creo que sí es imposible trabajar sobre algo que a uno no le interese. Este trabajo me ha servido, sobre todo, para desafiar mis propios prejuicios. Algunos.

Manuel Moreno: Si una entrevista dirigida es una conversación con un objetivo, uno debe tener la habilidad de saber qué se puede publicar y qué no se puede publicar, pero los puntos de vista distintos no impiden que se haga una buena entrevista. Es una cuestión de habilidad para llegar a alcanzar un objetivo. 
Paz Gómez: Yo no estoy de acuerdo.

Margarita: Yo creo que lo importante no es lo que se busca sino lo que se encuentra y qué comportamiento ético está uno dispuesto a seguir. Yo no hago entrevistas para provocar.

Matilde Fernández: De lo que se trata es de comprender. Creo que un antropólogo debe aparcar lo que es él mismo para conocer lo que es el otro.

Paz Gómez: Yo creo que tiene que haber necesariamente una pérdida entre el pensamiento que yo tengo, por tanto el que quiero hacerte llegar a ti, el que a ti te llega, lo que tú seleccionas de lo que te digo y lo que me devuelves. ¿Soy capaz de preguntar lo que quiero preguntar y el otro llega a entender lo que yo quiero saber?

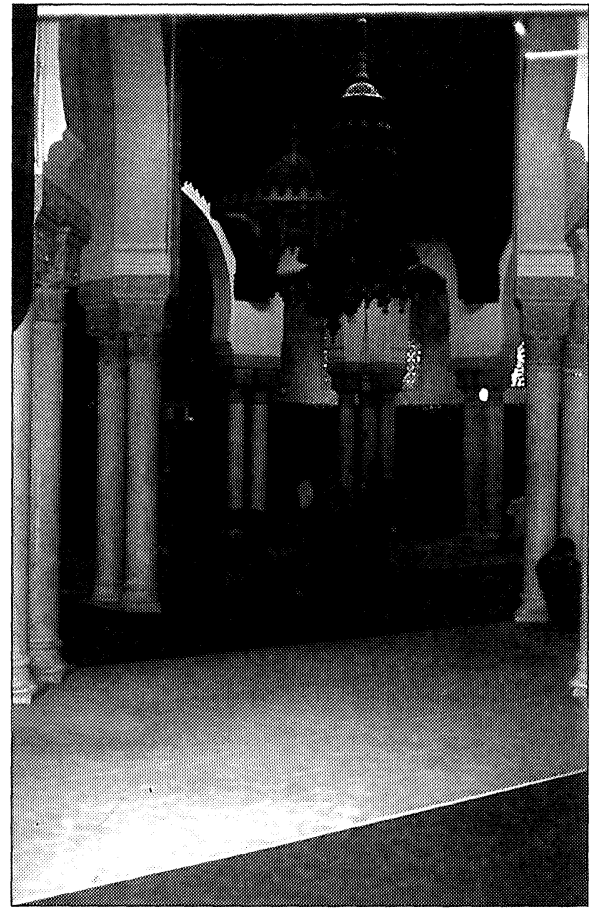

Figura 8.-Mezquita de París. Sala de oración de los hombres.

Margarita: Yo creo que no, que tus preguntas no te sirven, en absoluto, y por eso es por lo que digo que en una entrevista se buscan preguntas, no respuestas. Porque las tuyas no sirven de partida y, a veces, hasta son ofensivas.

Marisa González: Todo esto está muy bien y tenemos nuestras maravillosas entrevistas, nuestros intercambios de significados y procesamos todo este material. Con todo ello se puede hacer un análisis de discurso que es algo que a mí me parece muy bien porque lo que yo he visto que suelen hacer los antropólogos es estrictamente un análisis de contenido. A través de un análisis de discurso lo que haces es explorar las cosas implícitas o lo que el otro no ha dicho deliberadamente. Pero cuando tenemos todo esto, ¿cómo lo representamos?

Margarita: ¿Qué es lo que queremos representar?

Marisa González: De acuerdo 1) ¿qué queremos representar, 2) ¿cómo lo representamos? Supongamos que la traducción no es posible, entonces lo que no se puede traducir, lo que se nos escapa, el suplemento ese que como una especie de chicle... ¿cómo representamos eso?, ¿con un estilo indirecto?, ¿con un estilo directo? 
Margarita: ¿Tú has aprendido algo sobre los españoles conversos al Islam? Quiero decir, porque lo que he relatado es un desencuentro, una incapacidad. ¿Te has hecho una idea por mínima que sea?, ¿has aprendido algo desde que entraste por esa puerta?

Marisa González: Me he hecho una idea del desencuentro contigo.

Margarita: ¿Has visto a los conversos de una forma distinta desde que entraste por la puerta?

Marisa González: Totalmente de acuerdo, pero digo, más allá de relatar el desencuentro, ¿se podría dar la palabra al otro?

Margarita: De eso trata el trabajo de Cristina Sánchez, de cómo darle la palabra al otro.

Marisa González: Exponer la palabra del otro, reducirla y sin traducirla, de forma fragmentada.

Margarita: ¿Tú crees que eso es darle la palabra al otro?

Marisa González: No sé, pregunto.

Margarita: Yo creo que no, yo creo que eso no es darle la palabra al otro. Para mí la conclusión más interesante del trabajo de Cristina Sánchez es: En un trabajo de campo no podemos evitar las relaciones desigualitarias de poder, lo único que podemos hacer es expresar esa desigualdad, pero no podemos hacer hablar al otro en nuestros trabajos.

Marisa González: ¿Y una coautoría? Yo creo que es una cuestión de grado. Hay una diferencia notable entre yo traduzco con estilo indirecto al otro, a, segundo grado, yo no traduzco nada sino que transcribo lo que el otro dice tal cual lo ha dicho, tercer grado, yo le propongo al otro si tiene algún interés en participar en la cosa que estoy escribiendo y ser co-autor. Que no digo que en cada uno no esté filtrada la cuestión de la desigualdad. ¿sí o no? Es una pregunta.

Matilde Fernández: Yo personalmente me decantaría por re-escribir yo. Creo que se entiende mejor y que lo otro puede entorpecer mucho el entendimiento. Transcribir no es lo mismo que leer.

Margarita: Cualquier transcripción, por literal que sea, es una versión.

Paz Gómez: Yo creo que depende mucho del informante. Si yo me encuentro con un buen constructor de narraciones su discurso tienen valor por sí mismo. Yo después puedo trabajar sobre él, decir cosas sobre él, entre ellas por qué ha sido elegido, que me parece muy pertinente.

Matilde Fernández: Es que en una conversación uno puede repetir muchas veces una palabra, tartamudear, confundir una palabra por otra, ser reiterativo, etc. Y si lo transcribes así queda mucho más torpe. Es una opción.

Paz Gómez: Sí, tienes razón. También puedes proponer que lo lea en alto para reproducir el ritmo de la propia narración y volverle a dar la validez de una performance, ¿no? 
Margarita: Cristina Sánchez emplea una estrategia para incluir la voz del otro que consiste en invitar a su informante a compartir la ponencia o la conferencia que ella vaya a dar, repartiendo también el dinero que ella cobra. Pero creo que en la versión escrita no lo pretende y creo que es más honesto no pretenderlo. Yo lo único que busco en un trabajo es que las perplejidades o los intereses o las preguntas que yo me hago, otra persona me las devuelva de otra forma a través de una conversación. Es decir que me sacuda mi interlocutor. Y eso es lo mismo que yo pretendo con mis lectores, quizá a través de una estrategia menos adecuada puesto que un artículo provoca muchas menos emociones que una conversación, por el simple hecho de tener a una persona delante. Pero eso, en última instancia, depende mucho del azar porque lo que yo puedo pretender provocar en este momento, a lo mejor a la otra persona no le interesa.

Traude Müllauer-Seichter: ¿Y qué pasa en el caso de que los informantes estén muy interesados en que yo transmita sus intereses? Yo creo que eso te exige un control personal como investigador porque tampoco se puede uno dejar manipular por los intereses de los demás.

Margarita: Yo creo que si uno cree que debe contar determinadas cosas que la otra persona no va a aprobar, no porque se refieran a su intimidad o a su vida privada, sino que se trate de opiniones. Yo creo que se deben publicar, y luego a ver qué pasa.

Traude Müllauer-Seichter: $O$ cuando los informantes esperan que les eches una mano en un determinado movimiento, que es algo que yo he experimentado.

Paz Gómez: Son las deudas que uno no quiere asumir, iporque no puede!

Matilde Fernández: En cierta medida sí puedes y sí quieres asumirlas.

Paz Gómez: ¿Cómo solucionáis el problema de una persona que no quiere hablar?

Margarita: Pues: jadiós muy buenas! Has tenido una determinada relación con esa persona interesante, que te está diciendo un montón de cosas.

Matilde Fernández: De todas formas hay manera de abordar a la gente. Por ejemplo cuando hemos querido trabajar en Vallecas sobre la Guerra Civil y nos han dicho: "Yo sobre la Guerra Civil no hablo" y ahí se acabó, de ahí no pasas. Pero si llegas diciendo: "iqué tractor tan bonito!" y "¿le puedo hacer una foto?, ¿para qué lo usa?". Te terminan contando cómo en la Guerra Civil hicieron esto y lo otro. Es lo que decía Margarita: Se trata de evitar la pregunta directa.

Paz Gómez: Efectivamente a mí lo que me interesa es ver cómo se sitúa la gente en relación con lo que yo quiero saber. 
Matilde Fernández: Y desde luego es muy importante proporcionar un contexto.

Margarita: También existen otras estrategias, yo creo. Conozco una antropóloga española que se llama Begoña Aretxaga cuyo interés era trabajar sobre el I.R.A. hoy, y cuando llegó a hacer su trabajo de campo vio que era absolutamente imposible porque la gente se jugaba la vida con lo que le decía, y lo que se le ocurrió fue preguntar acerca de lo que había pasado hacía veinte años y que le contaran sus opiniones sobre ello. En ese momento las personas están proyectando lo que piensan sobre el presente también, y aunque no le vayan a contar lo que ocurrió en la bomba de ayer, está obteniendo comentarios sobre otras bombas similares. Cuando yo trabajé sobre el exilio argentino, el exilio había terminado y los exiliados estaban reflexionando sobre él. Quizá en pleno exilio no hubiera podido hacer el mismo trabajo.

Caridad Hernández: Una cosa es preguntar directamente y decir: "quiero esto" y otra muy distinta trabajar en un contexto a más largo plazo donde a uno ya le conocen, porque lleva un tiempo, y este tipo de trabajo permite una forma distinta de entrevistar y de comparar entrevistas.

Paz Gómez: de todas formas yo agradezco muchas veces más los fracasos que los aciertos directos, porque me permiten construir. Lo decíais el otro día: A veces dicen más las ausencias que las presencias. Ello le permite a uno poderse colocar. Cuando al empezar un trabajo uno es inmediatamente aceptado y todo resulta fácil, a mí se me encienden algunas luces que me indican que algo va mal.

\section{BIBLIOGRAFÍA CITADA}

BERnARD, H. Rusell. 1995. Research Methods in Anthropology. Qualitative and Quantitative Approaches. Walnut Creek: Altamira Press.

Briggs, Charles L. 1986. Learning How to Ask. A Sociolinguistic Appraisal of the Rol of the Interview in Social Sciences Research. Cambridge: Cambridge University Press.

Dijk, Teun A. Van. 1984. Prejudice in Discourse: Analysis of Ethnic Prejudice in Cognition and Conversation. Ámsterdam: John Benjamin Publishing Company.

- (ed.). 1985. Handbook of Discourse Analisis. Vol. 3. Discourse and Dialogue. Orlando: Academic Press.

- 1993. Elite Discourse and Racism. Londres: Sage Publications.

Ember, Carol R. y Melvin EmBer. 1988. Cultural Anthropology. Englewoods Clifts: Prentice Hall.

Fernández, Graciela. 2001. "Españolas por Alá". El Mundo. Magazine. 18 de febrero: 24-28.

KOTTAK, CONRAD P. 1987. Cultural Anthropology. Nueva York: Random House. 
MANZANO, EDUARDo. 2000. "La construcción histórica del pasado nacional", en S. Pérez Garzón (ed.), La gestión de la memoria. La historia de España al servicio del poder. 33-62. Barcelona: Crítica.

Olmo, MARGARITA DEL. 1990. La construcción cultural de la Identidad: inmigrantes argentinos en España. Madrid: Universidad Complutense.

- 2000. "Los conversos españoles al Islam: De mayoría a minoría por la llamada de Dios". Anales del Museo Nacional de Antropología 7: 13-40.

- 2001a. "El Madrid que mira hacia la Meca. La producción simbólica de alternativas sociales". RDTP 56 (1): 203-220.

- 2001b. "El velo de la discordia: un análisis del reflejo de la sociedad española en el velo de una conversa". Revista Internacional de Ciencias Sociales y Humanidades 11 (1): 9-18.

- 2002. La utopia en el exilio. Madrid: CSIC.

- en prensa. "Un efecto inesperado de la globalización: los conversos españoles al Islam". Barcelona: Anthropos.

RiCHARDS, LYN y TOM RichaRDS. 1994. "From Filing Cabinet to Computer", en Bryman y Burgess (eds.), Analyzing Qualitative Data: 146-172. Nueva York: Routledge.

SÁNCHEZ, PEDRO ANÝonio. 1995. "Los retos de la conversión". Verde Islam 3 (artículo disponible en internet: http://www.verdeislam.com/vi_03/VI_310.htm). 